\title{
$\therefore$ \\ A Study of the Influence of Sex Stereotyping on Choices of Postgraduate Medical Students
}

\section{IJCRR}

Section: Healthcare

ISI Impact Factor

(2019-20): 1.628

IC Value (2019): 90.81

$\operatorname{SJIF}(2020)=7.893$

(c) (i) (3)

Copyright@IJCRR

\section{Anna Elizabeth Mathew ${ }^{1}$, Crystal David John²}

\author{
'BA Economics, Department of Economics, Stella Maris College (Affiliated to the University of Madras), Cathedral Rd, Poes Garden, \\ Gopalapuram, Chennai 600o86, Tamil Nadu, India; 'Retired Professor, Department of Economics, Stella Maris College (Affiliated to the \\ University of Madras), Cathedral Rd, Poes Garden, Gopalapuram, Chennai 6ooo86, Tamil Nadu, India.
}

\section{ABSTRACT}

Introduction: Sex-based occupational segregation and sex stereotyping have been found to exist all over the world including in the medical field. This paper investigated if sex-based occupational segregation exists among post-graduate medical students in the selection of their specialisation in Tamil Nadu (which is a medical tourism hub), analysed sex stereotyping among these students and its effect on perceived earning capacity.

Objective: To investigate if sex-based occupational segregation exists in different medical specialisations based on speciality choices of postgraduate students. To study if sex stereotyping exists among medical students. To study how this bias influences the expected earning capacity of young medical professionals.

Methods Secondary data regarding student enrollment was collected from two out of the three government medical colleges in Tamil Nadu and the chi-square test was performed to study if there was any significant association between sex and speciality choice. Questionnaires were distributed to the students and the different specialities were divided into three categories - Surgical Speciality Clinical (MSC), Medical Speciality Clinical (MDC) and Medical Speciality Non-Clinical (MDNC). Interviews were also conducted. This was done to investigate if sex stereotyping exists.

Results: It was found that there existed significantly greater participation of men in the first category $(P=0.0001)$ and significantly greater participation of women in the third category $(P=0.001)$. Respondents believed that men were better suited for specialisations such as orthopaedics for reasons such as better perceived skill while women were better suited for dermatology and gynaecology due to patient preference. Participants also believed that higher incomes should be a greater determining factor in the choice of specialisations for men than for women.

Conclusion: The researcher thus concludes that occupational segregation based on sex exists among postgraduate medical students in Tamil Nadu and that sex stereotyping plays an important role in this.

Key Words: Education, Gender, Gender Roles, Medical Education, Sexism, Sex Stereotyping

\section{INTRODUCTION}

Sex-based occupational segregation refers to the distribution of employees across and within occupations based on sex. This results in some jobs being largely male populated and others, largely female. Recent advancements in women's rights have led to more women entering the labour force and occupying positions that they were historically denied. However, sex-based occupational segregation continues to exist.

Sex stereotyping, in this article, refers to the preconceived set of notions that individuals and groups have regarding the ideal behaviour of people based on their sex. Studies show that the stereotypical perceptions regarding men and women play a role in occupational segregation. ${ }^{1}$ Such sexbased occupational segregation is seen in the medical field as well. Despite the increasing number of women entering the medical field, it is seen that the specialisation choices of men and women tend to differ. ${ }^{2}$ Women are often fed negative attitudes regarding female surgeons that discouraged them from taking up surgery. ${ }^{3}$ Studies have also found that female doctors considered their domestic duties more seriously in determining their choice of specialisation than

\section{Corresponding Author:}

Anna Elizabeth Mathew, BA Economics, Department of Economics, Stella Maris College (Affiliated to the University of Madras), Cathedral Rd, Poes Garden, Gopalapuram, Chennai 600086, Tamil Nadu, India; Telephone: +91-7338701372; Email: annaelizabethmathew99@gmail.com

ISSN: $2231-2196$ (Print)

Received: 01.01 .2021
ISSN: 0975-5241 (Online)

Revised: 03.02 .2021
Accepted: 08.03 .2021
Published: 04.06 .2021 
did their male counterparts. ${ }^{4-6}$ Studies conducted in Nigeria Japan, Australia and France showed that sex played a role in the determination of medical speciality choices. ${ }^{6-9}$ Similar studies conducted in India have shown that sex differences in the choice of specialisation continue to exist. ${ }^{8-11}$

The sex variations in medical specialities due to sex stereotyping represents a colossal loss of potential as the personnel who may have been very well suited for the job don't end up participating in the speciality only because of the conventional beliefs and stereotypes. India is a country that is seeing speedy development in the healthcare sector. Chennai, the capital of Tamil Nadu (a southern state in India) is a medical hub attracting patients from all over the world on account of quality healthcare services provided at relatively affordable rates. In India, doctors choose their specialisation after the completion of their undergraduate MBBS degree. Several specialisation choices exist that can broadly be categorized into two - a post-graduate degree in general surgery (MS) or a post-graduate degree in general medicine (MD). The city of Chennai has four government medical colleges and several private medical colleges that offer postgraduate specialisations that are known to produce excellent doctors.

The present research project aims to fill the gaps in knowledge by determining whether sex-based occupational segregation exists and whether sex stereotypes influence the speciality choice of postgraduate medical students in government medical colleges in Tamil Nadu. The objectives of this study sets to investigate if sex-based occupational segregation exists in different medical specialisations based on speciality choices of postgraduate students, to study if sex stereotyping exists among medical students and to study how this bias influences the expected earning capacity of young medical professionals.

\section{MATERIALS AND METHDOS}

The study involved the use of both primary and secondary data. Secondary data was used to analyse the first objective and primary data was used for the analysis of the other objectives. The main statistical tools used were per cent ages, pie charts and the Chi-Square test. The Statistical Package for the Social Sciences (IBM SPSS version 2019) was used. The first objective (to investigate if sex-based occupational segregation exists in different medical specialisations based on speciality choices of postgraduate students) required an analysis of the data of existing postgraduate students to see if there existed specialisations that were dominated by those of a particular sex.

Secondary data regarding student enrolment was obtained from two out of the three government medical colleges that offer postgraduate study in Chennai. The study included only government colleges as students of private medical colleges pay different tuition fees for different specialisations which could be a major determinant of the speciality choice. The data obtained provided information on the students who had enrolled in the year 2017 for 23 different postgraduate medical specialisations. To facilitate the analysis, the 23 specialisations were grouped under different heads. Surgical specialities (MS) were grouped. Medical specialities (MD) were further grouped under clinical and non-clinical specialities. Note that clinical specialities involve patient contact while non-clinical specialities do not. The specialities in each category are specified in Table 1.

After categorizing the data, the Chi-Square test was run to identify if there was any association between sex and the categories of specialisation. The Chi-Square test was also run within each category to identify whether there is a statistically significant difference between the sexes.

Primary data was used to analyse objectives two and three which involved the investigation of the existence of sex stereotyping and the study of its effect on the expected earning capacity. A random sampling method was used to obtain the sample along with a structured questionnaire. The questionnaire had three domains - demographic details, factors affecting the choice and expected income. Questions were quantitative and respondents were required to select their responses from the given set of options. The questionnaire included questions on what the top two specialisation choices of the students were, why they preferred those specialities, which specialisations would be better suited for men and women and the reasons for the same. The questionnaire also included questions on whether respondents believed that men and women of the same specialisation tend to receive different pay and whether expected income should be a greater determinant for men when choosing their specialisation than for women. To analyse the differences in the responses for men and women, descriptive statistics were used. To analyse whether there was a significant difference in the responses of men and women, the Chi-Square test was used.

A study of this kind cannot be completed with the aid of a quantitative questionnaire alone. To accommodate multiple viewpoints and to provide an in-depth analysis, interviews were also conducted. An interview guide was prepared which included questions on whether the respondents believed occupational segregation exists, why they think it exists and what the problems with it were. Questions regarding earning capacity and general satisfaction with their speciality choices were also asked. Five students (two male and three female) were selected at random from different specialisations. Three professors from different colleges were also interviewed. Like the interviews conducted with the students, these too were highly informal. Once the data was obtained and the master table was prepared. 


\section{RESULTS}

The study shows that a total of 168 men and 172 women had enrolled to pursue their post-graduation in Madras Medical College and Stanley Medical College in the year 2017. Sex composition varied among the specialisations. Table 1 shows the distribution of men and women in the different categories of specialities.

The result of the Chi-Square test was that there was a statistically significant association between sex and the choice of specialisation $(\mathrm{P}=0.0001)$ with a contingency coefficient of 0.3 .

The test was run separately for each of the three categories to understand whether there was a statistically significant difference in the specialisation choices of men and women. The results were as follows:

\section{Category 1: Surgical Speciality - Clinical (MSC):}

In this category, men comprised $72.5 \%$ while women comprised $27.5 \%$. Upon analysis, it was found that significantly more men had chosen specialities under this category $(\mathrm{P}=0.0001)$.

\section{Category 2: Medical Speciality - Clinical (MDC)}

In this category, men comprised $45.3 \%$ of the population while women comprised $54.7 \%$. Upon analysis, it was found that there exists no significant difference in the participation of men and women in this category $(\mathrm{P}=0.206)$.

\section{Category 3: Medical Speciality - Non-Clinical (MDNC)}

In this category, men comprised $29.4 \%$ of the population while women comprised $70.6 \%$. It was found that there exists significantly greater participation of women $(\mathrm{P}=0.001)$.

The next stage of the study involves the analysis of sex stereotyping among postgraduate medical students. The questionnaire was distributed online to 55 respondents-37 (67.3\%) women and $18(32.7 \%)$ men who were sampled randomly. $23(41.8 \%)$ students were in their first year, eight $(14.5 \%)$ in their second year and 24 (43.6\%) in their final year. $50.1 \%$ of the sample was unmarried while the rest was married. The study had respondents from numerous specialisations. The specialisations represented were Biochemistry, Dermatology, Obstetrics and gynaecology, Paediatrics, General Medicine, Vascular Surgery, Orthopaedics, Community Medicine, Anaesthesiology, Ophthalmology, Pathology, General surgery, TB and Pulmonary Medicine, Pathology, ENT and Radio Diagnosis.

When assessing gender differences, it was found that the most preferred speciality for women was dermatology while radio diagnostics, ophthalmology and gynaecology were the preferred specialities that followed (Figure 1).
On the other hand, orthopaedics was the most preferred specialisation for men while general medicine and general surgery followed closely (Figure 2).

The respondents were then asked what factors other than their skill and aptitude determined their top speciality choices. For women, it was seen that patient contact (or lack), compatibility with family life and convenient working hours were the most popular factors. It was also observed that expected income featured relatively low for women (Table 2). On the other hand, it was seen that expected income was the most important factor followed by status or prestige value and patient contact that determine male medical students' speciality choices. This was followed by compatibility with family life (Table 2).

To identify if certain specialisations were considered stereotypically male or stereotypically female, respondents were asked to choose which specialisations were better suited for men and women. They were also asked to justify their answers. For the specialisation that would better suit men, an equal number of female responses indicated that men would excel at Orthopaedics and that no specialisation exists for which women are better suited. This is seen in Figure 3. Men, on the other hand, responded that they would be better suited for Orthopaedics. This was closely followed by General Surgery and an equal number of responses stating that no such specialisation exists for which men are better suited. (Fig 4).

When analysing the reasons for the same, it was found that women did not believe that men would be better off in certain specialisations (Table 3) On the other hand, men attributed the reasons for being better suited to 'skill and talent' followed by 'better suited for working hours' (Table 3).

When asked which specialisations women would be better suited for, female respondents overwhelmingly chose Dermatology closely followed by Obstetrics and Gynaecology. An equal number of respondents also said that they did not agree that women would be better suited for specific specialisations (Figure 5). Male respondents stated that women would be better suited in the specialisations of Obstetrics and Gynaecology followed by dermatology. An equal number of respondents also said that they did not believe women would be better suited for any given specialisation. (Figue 6).

The responses received from women on the factors that are responsible for their being better suited for specific specialisations largely rested on suitable working hours. Women also believed that they would be better suited for certain specialisations as patients would prefer female doctors (for specific specialisations). Many respondents also disagreed and stated that they did not think that women would be better suited for certain specialisations (Table 5). Male respondents also attributed similar factors to the ones chosen by women. Patient preference ranks only marginally below better suited for working hours in their opinion (Table 4). 
The final question in this section focus on identifying the reasons that motivated the respondents to pick their chosen specialisation. It was seen that for male respondents, skill and aptitude was the primary reason for the selection of specialisation while expected income came second. Note that other reasons include greater free time to pursue other hobbies (Table 4).

Female respondents too showed similar results with skill and aptitude being the primary factor (Table 4). Note that other reasons all had to do with passion for the field of study. When analysing the impact of sex stereotyping on the earning capacity of men and women, it was found that most men and women did not believe that there would be a difference in pay (earning capacity) within specialisations between men and women. When the respondents were asked if they believed that earning capacity should be a greater determining factor in the selection of the specialisation for men than it is for women, a majority answered in the affirmative. This response was received from both men and women.

The second part of the analysis involved interviewing professors and students. The first professor who was interviewed had an MD in anesthesiology. Speaking within the walls of the institution, she agreed that sex stereotyping of medical specialisations was rampant but did not see anything wrong with it. She argued that women must perform their domestic duties and take care of the house. She did not think that the impact on income if there was one at all, was significant because all doctors tend to earn a lot of money. She also firmly believed that there was no need to do away with the stereotyping as it was not causing any harm.

The second professor who was interviewed had similar views. Arguing that there was no need to correct a problem that does not harm, she said that both women and men should be encouraged to pursue careers as medical professionals. The choice of specialisation seemed too trivial a detail to worry about. She also argued that even if such a problem was identified, very little could be done about it. The third professor who was interviewed spoke about the lack of same-sex role models within the field of specialisation. He believed that this could help solve the problem as students would be encouraged to pursue those specialisations. He remarked on the need for gender equality in the field of orthopaedic surgery and stated that the need for "'superhuman strength", was an exaggeration.

The students who were interviewed spoke about practical concerns. Two female students of MD Pathology (one of whom was married) remarked on the difficulty of being 'oncall as women. They stated that concerned family members would not be too happy about their working late at night. However, they too believed that they would not be losing out. They were happy with their specialisations and did not wish to change them. A third female medical student believed that it was all a matter of convenience. Her chosen specialisation of Dermatology was ideal for her as she wanted to treat patients. She remarked that while sex stereotyping of medical specialities may exist, she was happy with her choice of speciality.

The last student to be interviewed was a second-year medical student of Orthopaedics. He staunchly believed that gender stereotyping is a thing of the past but argued that orthopaedics was better suited for men as a great deal of physical strength was required. Likening it to 'carpentry', he argued that it would be very difficult for women to succeed in the field but not impossible. He thought that all students who make specialisation choices do not consider their sex.

\section{DISCUSSION}

It is therefore at this juncture when the study has been completed that the results are discussed. It was found that certain specialisations like Obstetrics and Gynaecology were more female populated while Orthopaedic surgery was more male populated. These results corroborate with the ones obtained by other studies around the world. ${ }^{11-19}$ When analysing sex stereotyping, it was found through the questionnaire survey and the interviews that suitable working hours play a major role in determining women's participation in a specialisation. Moreover, expected earnings were a greater determining factor for men than for women. The study shows that women are heavily entrusted with the task of domestic responsibilities. On the other hand, men seem to bear the burden of earning income. The analysis of the effects on earning capacity showed that men and women do not perceive unequal pay within the specialisation on account of sex-based discrimination. However, men and women do think that earning capacity should matter more to men than it should to women. Some specific findings of the study have been analysed below to provide more clarity.

In Category 2 (MDC), the high concentration of women in MD Obstetrics and Gynaecology (which was later found to be due to perceived patient preference) could account for the lack of significant variation in the participation of men and women. The larger participation of women in category 3 (MDNC) can be attributed to the scheduled working hours and lack of emergencies.

It was found that female respondents didn't think that certain specialities were better suited for men. This is a slight contradiction but can be resolved. Note that in Table 5, all responses categorized under 'other' spoke about the physical strength required to become an orthopaedic surgeon. Thus, when put together with skill or talent, the number of responses for 'skill or talent' and 'I do not agree that men are better suited' adds up. However, the study is not without its limitations. The sample size was very small (although fairly rep- 
resentative of the population). The disproportionality of men and women in the study could have affected the findings. More research on how such sex stereotypes are ingrained in people is necessary.

\section{CONCLUSION}

As the curtains are drawn for this study, it is important to understand that all the above results indicate the existence of sex stereotyping in the medical profession. The results indicate that sex plays a significant role in the choice of medical speciality. The best doctors are the ones who are good at what they do. Factors such as their sex should not affect specialisation choices and methods to eradicate it must be devised.

\section{ACKNOWLEDGEMENT}

The authors acknowledge the immense help received from the scholars whose articles are cited and included in references of this manuscript. The authors are also grateful to authors/editors/publishers of all those articles, journals and books from which the literature for this article has been reviewed and discussed.

Conflict of Interest and Source of Funding: The authors declare that there is no conflict of interest and no funding was obtained.

Individual Authors' Contribution: Dr. Crystal David John contributed to the conception of the topic, editing of the drafts and Anna Elizabeth Mathew contributed to the design, data collection, analysis, interpretation and manuscript preparation.

\section{REFERENCES}

1. Anker R, International Labour Office. Gender and Jobs: Sex Segregation of Occupations in the World. International Labour Organization; 1998;444.

2. Kruijthof CJ, van Leeuwen CD, Ventevogel P, van der Horst HE, van Staveren G. Career perspectives of women and men medical students. Med Educ. 1992;26(1):21-6.
3. Bucknall V, Pynsent PB. Sex and the orthopaedic surgeon: a survey of patient, medical student and male orthopaedic surgeon attitudes towards female orthopaedic surgeons. Surgeon. 2009;7(2):89-95.

4. Madhavrao C, Mythili Bai K. Knowledge Attitude And Practices Towards Principles Of Research Among Medical Postgraduates In A Teaching Tertiary Care Centre. Int J Curr Res Rev.8(2):1-7

5. Harris MG, Gavel PH, Young JR. Factors influencing the choice of the speciality of Australian medical graduates. Med J Aus. 2005;83(6):295-300.

6. Rouprêt M, Maggiori L, Lefevre JH. Upcoming female preponderance within surgery residents and the association of sex with the surgical career choice in the new millennium: results from a national survey in France. Am J Surg. 2011;202(2):237-42.

7. Eze BI, Okoye OI, Maduka-Okafor FC, Aguwa EN. Factors Influencing Choice of Medical Specialty of Preresidency Medical Graduates in Southeastern Nigeria. J Grad Med Educ. 2011;3(3):367-71.

8. Fukuda Y, Harada T. Gender differences in speciality preference and mismatch with real needs in Japanese medical students. BMC Med Educ. 2010;11:10:15.

9. Subba SH, Binu VS, Kotian MS, Joseph N, Mahamood AB, Dixit N, et al. Future specialization interests among medical students in southern India. Natl Med J India. 2012;25(4):226-9.

10. Bhargava G. Sex-stereotyping and sex-congruency: Components in the sex role definition of medical specialities in India. Soc Sci Med. 1983;17(15):1017-26.

11. Bhadra M. Indian Women in Medicine: An Enquiry Since 1880: Indian Anthropologist. 2011;41(1);17-43.

12. Bergquist SR, Duchac BW, Schalin VA, Zastrow JF, Barr VL, Borowiecki T. Perceptions of freshman medical students of gender differences in medical speciality choice. J Med Educ. 1985;60(5):379-83.

13. Pawełczyk A, Pawełczyk T, Bielecki J. Differences in medical specialty choice and in personality factors among female and male medical students: Pol Merkur Lekarski. 2007;23(137):3636.

14. Park J, Minor S, Taylor RA, Vikis E, Poenaru D. Why are women deterred from general surgery training? Am J Surg. 2005;190(1):141-6.

15. Rohde RS, Wolf JM, Adams JE. Where Are the Women in Orthopaedic Surgery? Clin Orthop Relat Res. 2016;474(9):1950-6.

16. Quadagno J. Occupational Sex-Typing and Internal Labor Market Distributions: An Assessment of Medical Special Ties. Soc Probl. 1976;23(4):442-53.

17. Delorey C, More ES. Restoring the Balance: Women Physicians and the Profession of Medicine, 1850-1995. J Public Health Policy 2003;24(6):483.

18. Lovett KF, Ross DA. Discrimination against women in medicine: lessons from Tokyo. Br Med J. 2018;3;362:k3685.

Table 1: Distribution of men and women in the different categories of specialities

\begin{tabular}{lcccccccc} 
Course & $\begin{array}{c}\text { Madras Medical } \\
\text { College }\end{array}$ & \multicolumn{2}{c}{$\begin{array}{c}\text { Stanley Medical } \\
\text { College }\end{array}$} & \multicolumn{2}{c}{ Total } & & Category \\
& M & F & M & F & Total Men & Total Women & MDNC \\
Anatomy & 0 & 4 & 1 & 1 & 1 & 5 & MDNC \\
Forensic Medicine & 3 & 0 & - & - & 3 & 0 & MDNC \\
Pharmacology & 1 & 3 & 0 & 2 & 1 & 5 & MDNC \\
Physiology & 1 & 4 & 1 & 1 & 2 & 6 &
\end{tabular}


Table 1: (Continued)

\begin{tabular}{|c|c|c|c|c|c|c|c|}
\hline \multirow[t]{2}{*}{ Course } & \multicolumn{2}{|c|}{$\begin{array}{c}\text { Madras Medical } \\
\text { College }\end{array}$} & \multicolumn{2}{|c|}{$\begin{array}{c}\text { Stanley Medical } \\
\text { College }\end{array}$} & \multicolumn{2}{|c|}{ Total } & \multirow[t]{2}{*}{ Category } \\
\hline & $\mathbf{M}$ & $\mathbf{F}$ & $\mathbf{M}$ & $\mathbf{F}$ & Total Men & Total Women & \\
\hline Social and Preventive Medicine & 2 & 1 & o & 5 & 2 & 6 & MDC \\
\hline Radio Therapy & 1 & 4 & - & - & 1 & 4 & MDC \\
\hline Anaesthesiology & 9 & 13 & 1 & 6 & 10 & 19 & MDC \\
\hline Biochemistry & 1 & 2 & o & 4 & 1 & 6 & MDNC \\
\hline Dermatology & 5 & 5 & 2 & 7 & 7 & 12 & $\mathrm{MDC}$ \\
\hline General Medicine & 18 & 6 & 19 & 4 & 37 & 10 & MDC \\
\hline Geriatrics & 2 & 1 & - & - & 2 & 1 & MDC \\
\hline Microbiology & 2 & 8 & 1 & 1 & 3 & 10 & MDNC \\
\hline Obstetrics and Gynaecology & o & 17 & o & 8 & o & 25 & MDC \\
\hline Paediatrics & 10 & 6 & o & 4 & 10 & 10 & MDC \\
\hline Pathology & 1 & 9 & o & 3 & 1 & 12 & MDNC \\
\hline Physical Medicine and Rehabilitation & 1 & 1 & - & - & 1 & 1 & MDC \\
\hline Psychiatry & 3 & 7 & 2 & 2 & 5 & 9 & MDC \\
\hline Radio Diagnosis & 3 & 2 & 5 & 2 & 8 & 4 & MDNC \\
\hline Tuberculosis and Respiratory Diseases & 2 & 1 & 5 & 1 & 7 & 2 & MDC \\
\hline ENT & 3 & 3 & 3 & 2 & 6 & 5 & MSC \\
\hline General Surgery & 16 & 4 & 20 & 2 & 36 & 6 & MSC \\
\hline Ophthalmology & 1 & 11 & 1 & 3 & 2 & 14 & MSC \\
\hline Orthopaedics & 13 & o & 9 & o & 22 & o & MSC \\
\hline
\end{tabular}

Table 2: Factors that determined men and women's top two speciality choices

\begin{tabular}{lcc} 
Factor & \% age of women & Percentage of men \\
Convenient working hours & 23.6 & 13.2 \\
Expected Income & 9.1 & 28.9 \\
Compatible with family life & 23.6 & 18.4 \\
Patient contact (or lack) & 36.4 & 21.1 \\
More time to spend with kids & 3.6 & 13.2 \\
Status or prestige value & 3.6 & 5.3 \\
\hline
\end{tabular}

Table 3: Reasons due to which respondents (men and women) thought men would be better suited for certain specialities

\begin{tabular}{|c|c|c|c|c|}
\hline \multirow[b]{2}{*}{ Reason } & \multicolumn{2}{|c|}{$\begin{array}{l}\text { Reasons due to which respondents thought } \\
\text { men would be better suited }\end{array}$} & \multicolumn{2}{|c|}{$\begin{array}{l}\text { Reasons due to which respondents thought } \\
\text { women would be better suited }\end{array}$} \\
\hline & Women & Men & Women & Men \\
\hline Skill or talent & $29.7 \%$ & $38.5 \%$ & o\% & o\% \\
\hline $\begin{array}{l}\text { Better suited for working } \\
\text { hours }\end{array}$ & $16.2 \%$ & $30.8 \%$ & $41 \%$ & $39.1 \%$ \\
\hline Patient preference & $8.1 \%$ & $11.5 \%$ & $20.5 \%$ & $30.4 \%$ \\
\hline Other & $8.1 \%$ & $15.4 \%$ & $28.2 \%$ & $4.3 \%$ \\
\hline I don't agree & $37.86 \%$ & $3.8 \%$ & $10.3 \%$ & $26.1 \%$ \\
\hline
\end{tabular}


Table 4: Reason for choice of specialisation of respondents

\begin{tabular}{lcc} 
Reason & \% women & $\%$ men \\
Familial pressure/persuasion & $5 \cdot 3$ & 10 \\
Skill and aptitude & 57.9 & 50 \\
NEET score & 10.5 & 10 \\
Sex and gender & 10.5 & 10 \\
Other & 15.8 & 20 \\
\hline
\end{tabular}

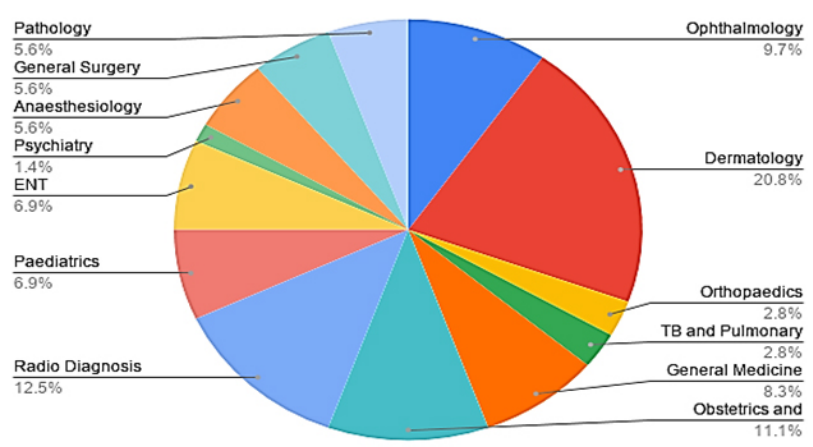

Figure 1: Women's top two speciality choices (Source- Primary data).

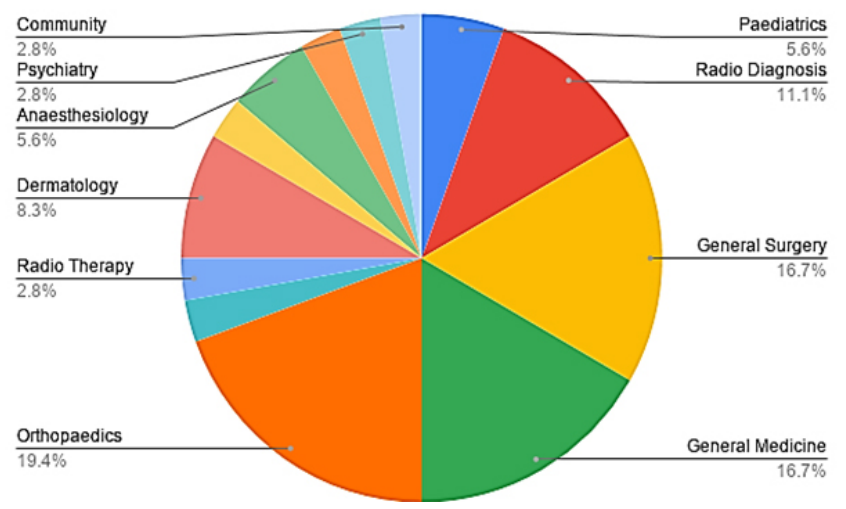

Figure 2: Men's top two speciality choices (Source- Primary data).

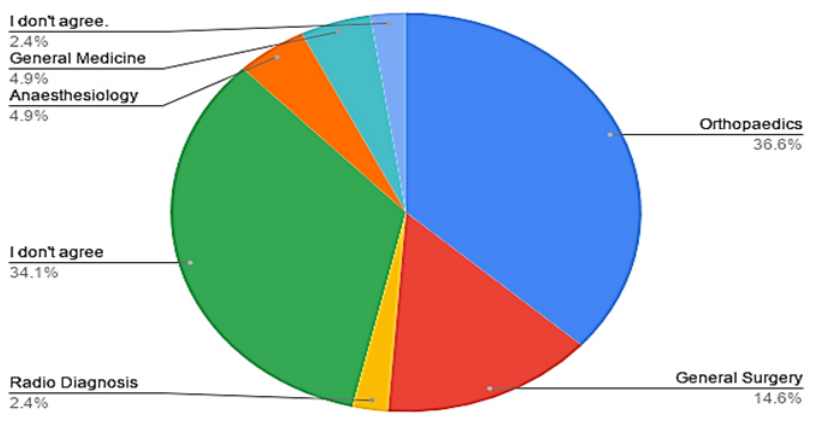

Figure 3: The specialities that were perceived better suited for men (by women).

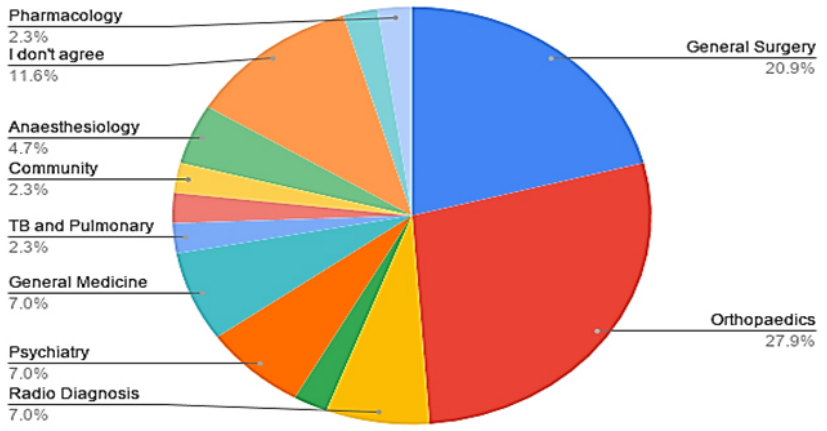

Figure 4: The specialities that were perceived better suited for men (by men).

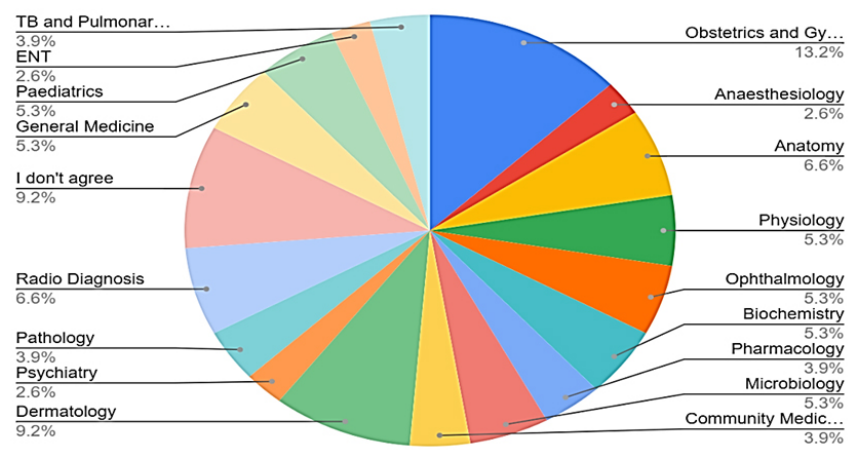

Figure 5: The specialisations that were perceived better suited for women (by women).

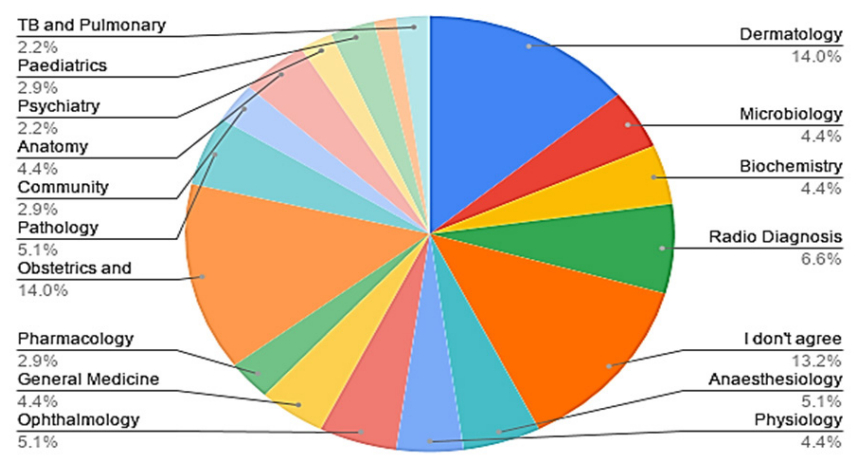

Figure 6: The specialisations for which women were perceived better suited (by men). 